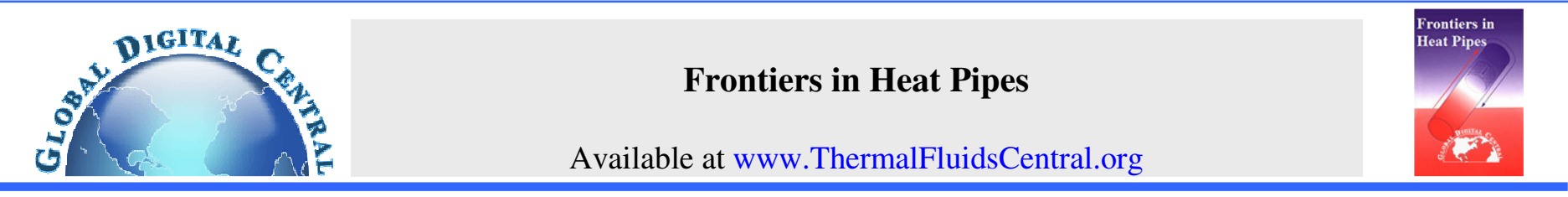

\title{
LAMINATION AND CHARACTERIZATION OF A POLYETHYLENE- TEREPHTHALATE FLEXIBLE MICRO HEAT PIPE
}

\author{
Guan-Wei Wu, Sih-Li Chen, Wen-Pin Shih ${ }^{*}$ \\ ${ }^{a}$ Department of Mechanical Engineering, National Taiwan University, Taipei,10617, Taiwan
}

\begin{abstract}
A polyethylene-terephthalate (PET) flexible micro heat pipe (FMHP) for heat dissipation has been fabricated and tested. The structure of flexible heat pipe consists of PET, $\mathrm{Cu}$ tape, $\mathrm{Cu}$ mesh and rubber. These materials are all flexible and inexpensive. Therefore, the heat pipe can bend and the wick structure will not collapse. Besides, the fabrication process can reduce both the material cost and machining time. Experiment results reveal that the minimum thermal resistance in this FMHP is $0.157^{\circ} \mathrm{C} / \mathrm{W}$.

Keywords: polyethylene-terephthalate, flexible, micro heat pipe
\end{abstract}

\section{INTRODUCTION}

For developing high-performance portable appliances with light weight and slim body, consumer electronics will require higher density mounting. Therefore, heat dissipation becomes an extremely important issue for electronics production. Heat pipe is a two-phase heat transfer exchanger with a very high thermal conductivity. The working fluid is filled into the heap pipe in vacuum. When the working fluid absorbs the heat from the heat source, it evaporates at the boiling point and the vapor delivers to the cooling end. Then the vapor releases heat and condenses to liquid. The wick supplies capillary force, facilitating the liquid to return to the heat source again. This two-phase thermal cycle needs minimal temperature gradients by enthalpy difference between phase changes (Yau and Ahmadzadehtalatapeh, 2010).

Conventionally, heat pipe are manufactured by metals such as aluminum and copper (Take and Webb, 2001; Lim et al., 2008). Many reports focused on micro heat pipe fabrication using silicon wafer for patterning hundred-micrometer structures (Berre et al., 2003). Although such materials could against high pressure difference, they have low or even no flexibility and are expensive (Sobhan et al., 2007). In recent years, a novel fabrication method has been applied to produce microchannel or package material in the flexible heat pipe (Oshman et al., 2009; Lin et al., 2009; Tanaka et al., 2009).

In this paper, the flexible polyethylene-terephthalate (PET) plastic film is used to replace the metal as the package material of the heat pipe. A relatively simpler approach to fabricate flexible micro heat pipe (FMHP) by lamination is also presented.

\section{STRUCTURE DESIGN OF MICRO HEAT PIPE}

The structure of flexible heat pipe consists of PET, $\mathrm{Cu}$ tape, $\mathrm{Cu}$ mesh and rubber, as shown in Fig.1. The width and length of the presented heat pipe are $20 \mathrm{~mm}$ and $110 \mathrm{~mm}$, respectively (Fig. 2). The total thickness of the heat pipe is $1.8 \mathrm{~mm}$. The capillary structure is made of $\mathrm{Cu}$ mesh, allowing the condensed liquid to go to the evaporator (liquid line). The gap between the upper and lower $\mathrm{Cu}$ mesh is supported by rubber, and the vapor will pass through this channel gap to the condenser (vapor line).

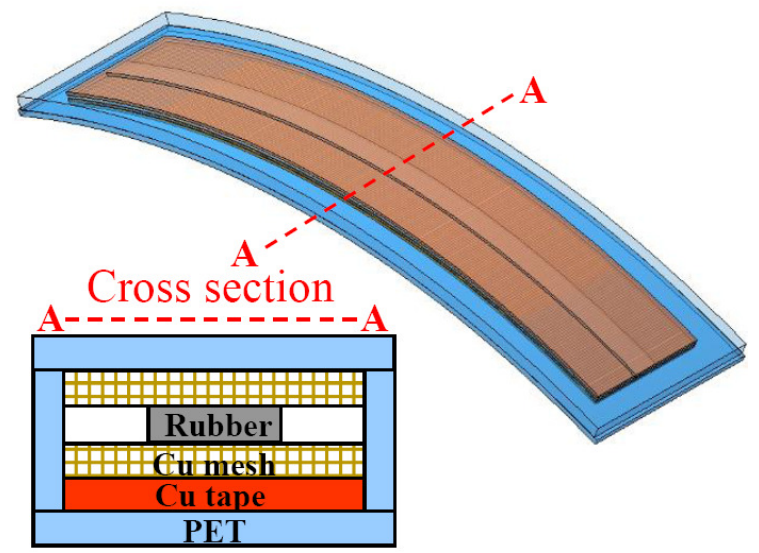

Fig. 1 Structure of the flexible heat pipe

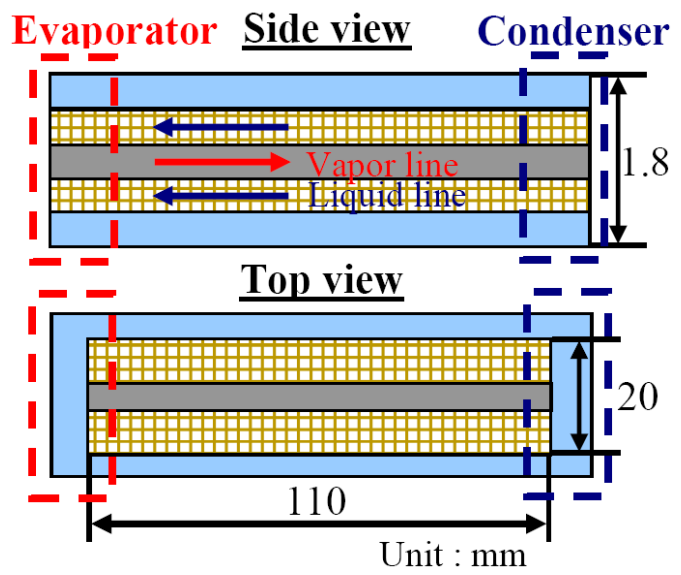

Fig. 2 Dimensions of the flexible heat pipe

Corresponding author. Email:wpshih@ntu.edu.tw 


\section{FABRICATION PROCESS}

To fabricate the FMHP, the PET is firstly cut into two areas and attached to a $\mathrm{Cu}$ tape, as shown in Fig. 3(a). The function of these two bare areas for the $\mathrm{Cu}$ tape is to contact the heat source and heat sink directly. Then the $\mathrm{Cu}$ mesh, rubber and another $\mathrm{Cu}$ mesh are attached layer by layer, as shown in Figs. 3(b) and (c). The PET is covered on the upper $\mathrm{Cu}$ mesh. Finally, a hot laminator is used for bonding the top and the bottom PET layers, as shown in Fig. 3(d).

(a) Cutting PET

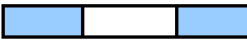

(b) Attaching $\mathrm{Cu}$ tape on PET

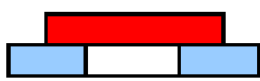

(c) Attaching $\mathrm{Cu}$ mesh and rubber

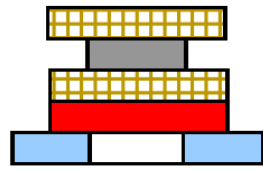

(d) Applying PET and hot lamination

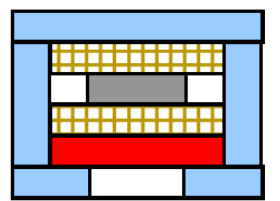

g. 3 Process for fabricating flexible heat pipe

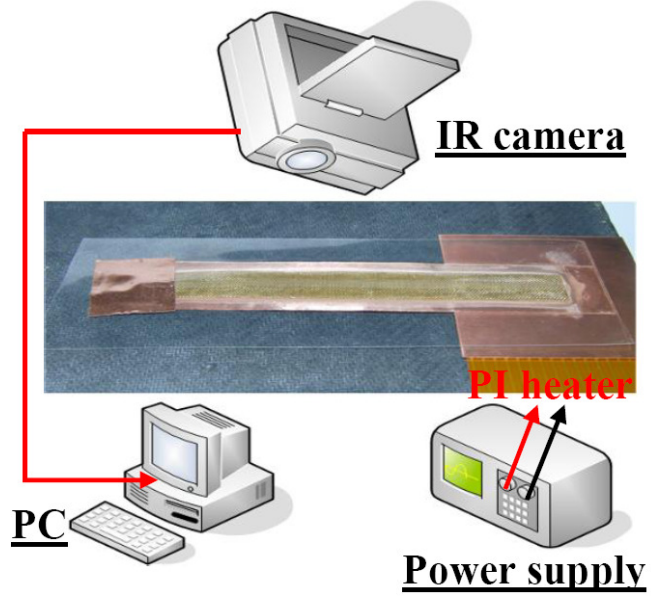

Fig. 4 Experiment set-up

Table 1 Specifications of the FMHP.

\begin{tabular}{|c|c|}
\hline Packaging material & PET \\
\hline Wick structure & Cu mesh \\
\hline Working fluid & Methanol \\
\hline Evaporator & PI heater \\
\hline Condenser & Natural convection \\
\hline Heat pipe width $(w)$ & $2 \mathrm{~cm}$ \\
\hline Heat pipe height $(h)$ & $1.8 \mathrm{~mm}$ \\
\hline $\begin{array}{c}\text { Length between evaporator and } \\
\text { condenser }\left(L_{e f f}\right)\end{array}$ & $7.5 \mathrm{~cm}$ \\
\hline
\end{tabular}

\section{EXPERIMENT SET-UP AND PROCEDURE}

An infrared (IR) camera, NEC TVS-500EX, is used to measure the thermal resistance of the heat pipe. The temperature measurement range and wavelength are $-40-500{ }^{\circ} \mathrm{C}$ and $8-14 \mu \mathrm{m}$, respectively. A power supply provides the power to the copper/polyimide heater as the heating source to drive the working fluid inside heat pipe, as shown in Fig. 4. The condensation section is cooled using air by natural convection and the ambient temperature is kept at $25^{\circ} \mathrm{C}$.

\section{RESULTS OF EXPERIMENT}

\subsection{Thermal Resistance Test at Horizontal Orientation}

When the working fluid, methanol, absorbs the heat until reaching its boiling point, it evaporates and goes to the condenser along the vapor line, as shown in Fig. 5. The IR image of the working heat pipe with different input powers at $36.9 \%$ filling ratio is shown in Fig. 6. For the input power larger than $4.7 \mathrm{~W}$, the heat will be delivered from the evaporator to the condenser with increasing input power.

The measured IR image of the FMHP is shown in Fig. 7. The red and black numbers are the highest and lowest temperature in the square area, respectively. The thermal resistance, $R_{t}$, is calculated by

$$
R_{t}=\frac{T_{e}-T_{C}}{W}
$$

where $T_{e}\left({ }^{\circ} \mathrm{C}\right)$ the evaporator temperature, $T_{c}\left({ }^{\circ} \mathrm{C}\right)$ the condenser temperature, and $W$ (Watts) the input power.

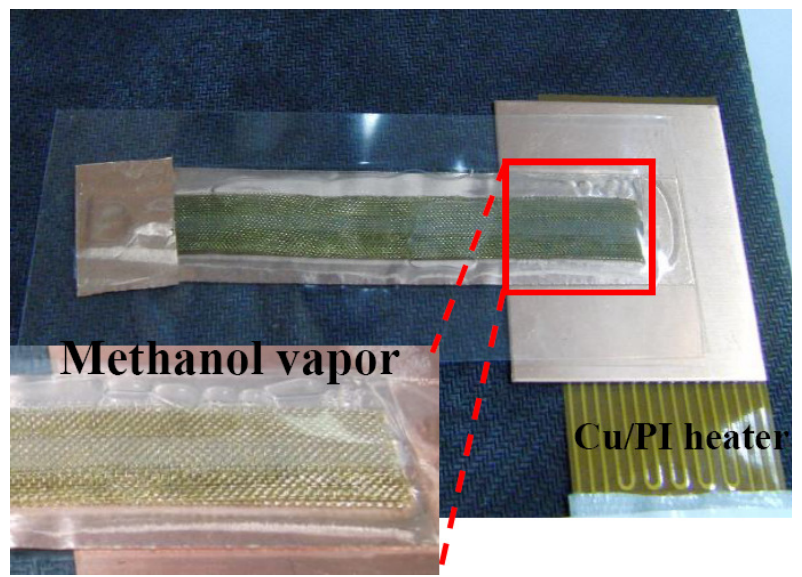

Fig. 5 Methanol vapor in the fabricated micro heat pipe

Filling ratio : $36.9 \%$

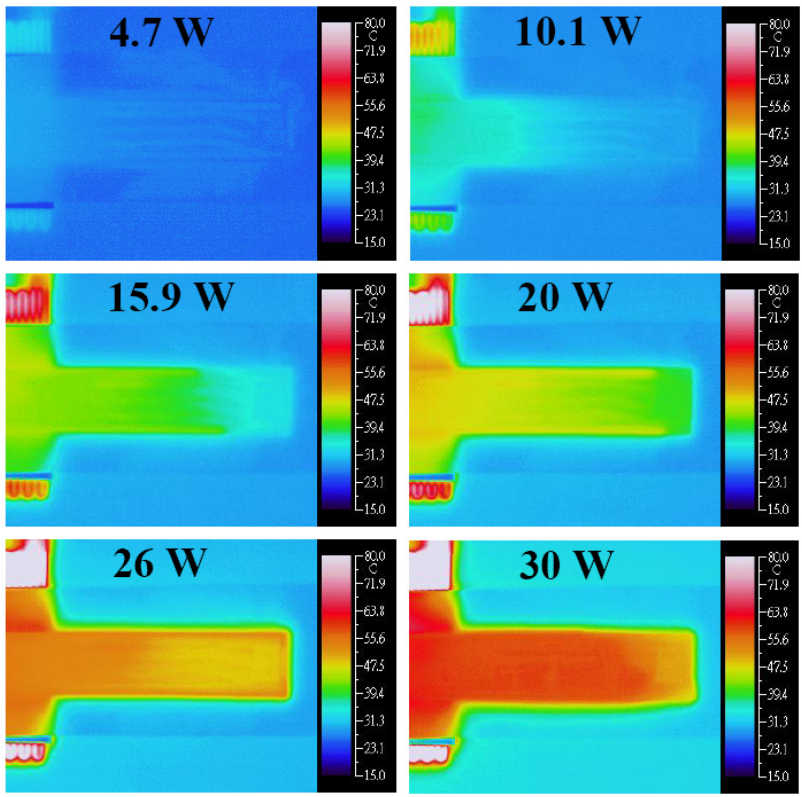

Fig. 6 IR image of FMHP at different input powers 
Input power : $26(W)$, Filling ratio : 36.9\%

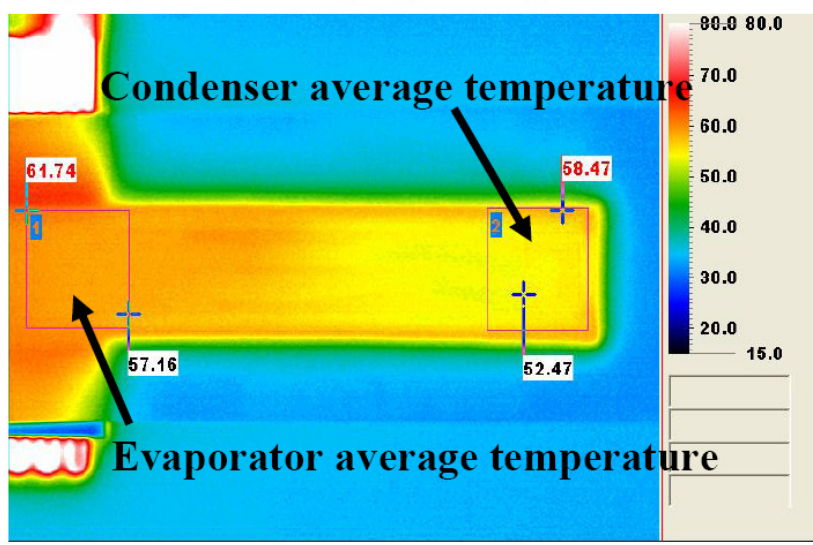

Fig. 7 IR image for calculating the average temperature of evaporator and condenser

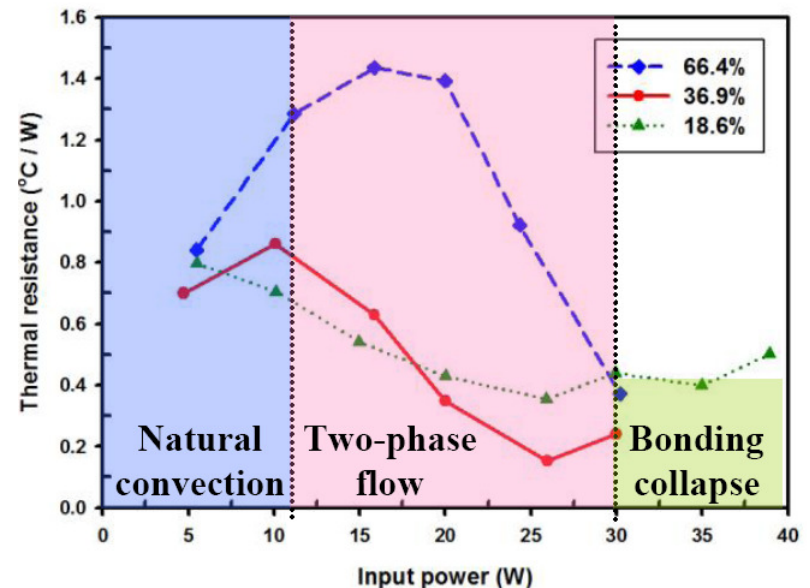

Fig. 8 Thermal resistance as a function of input power at different filling ratios
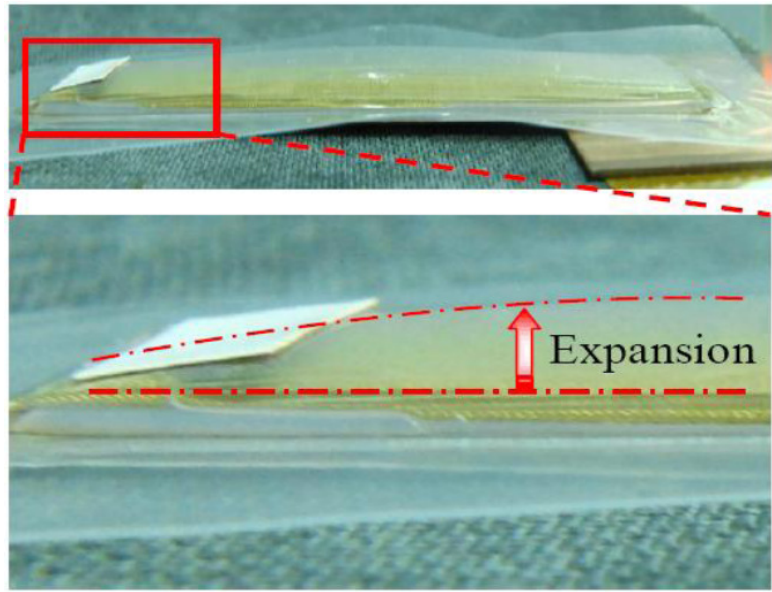

Fig. 9 Delamination in FMHP

The minimum thermal resistance of FMHP occurs at $26 \mathrm{~W}$. The average temperatures in the evaporator and the condenser are $58.94{ }^{\circ} \mathrm{C}$ and $54.86{ }^{\circ} \mathrm{C}$, respectively when the input power is $26 \mathrm{~W}$. Therefore, the thermal resistance of the fabricated heat pipe is $0.157{ }^{\circ} \mathrm{C} / \mathrm{W}$, which is suitable for practical applications.

The results of the experiment on measuring the thermal resistance with variation input powers at $18.6 \%, 36.9 \%$ and $66.4 \%$ filling ratios are shown in Fig. 8. Three operating conditions could be observed in the FMHP. When the input power is smaller than $10 \mathrm{~W}$, the methanol is just under natural convection in liquid phase. If the input power is between 10-30 W, a thermal cycle of two-phase flow is generated inside the heat pipe. Under this condition, the heat will rapidly transfer from the evaporator to the condenser. However, when the input power is larger than $30 \mathrm{~W}$, the PET will be delaminated because of high methanol vapor pressure at $36.9 \%$ and $66.4 \%$ filling ratios, as shown in Fig. 9.

At low filling ratio, though the methanol vapor has lower flow resistance and higher drive pressure, a little working fluid takes participation in the heat exchange at the evaporator, the heat is delivered finitely to the condenser. At high filling ratio, more heat could be taken to the condenser but the flow resistance is higher and the drive pressure is lower (Lips et al., 2010). In this experiment, the optimal filling ratio is $36.9 \%$ for the highest thermal conductivity.

The effective thermal conductivity, $K_{e f f}$, is (El-Nasr and S. M. ElHaggar, 1996; Dorf, 2004)

$$
K_{e f f}=\frac{Q_{i n} L_{e f f}}{A_{e f f}\left(T_{e}-T_{c}\right)}
$$

where $Q_{i n}$ the power input, $A_{\text {eff }}$ the cross-sectional area of the heat pipe, $L_{e f f}$ the effective length between the evaporator and condenser, $T_{e}$ the average temperature of the evaporator, and $T_{c}$ the average temperature of the condenser. Fig. 10 is the effective thermal conductivity as a function of the input power at different filling ratios.

The maximum effective thermal conductivity of FMHP occurs at $26 \mathrm{~W}$. The effective area and length is $3.6 \times 10^{-5} \mathrm{~m}$ and $0.075 \mathrm{~m}$, respectively. The temperature difference between the evaporator and the condenser is $4.08 \mathrm{~K}$. Therefore, the effective thermal conductivity is $13261 \mathrm{~W} / \mathrm{m} * \mathrm{~K}$.

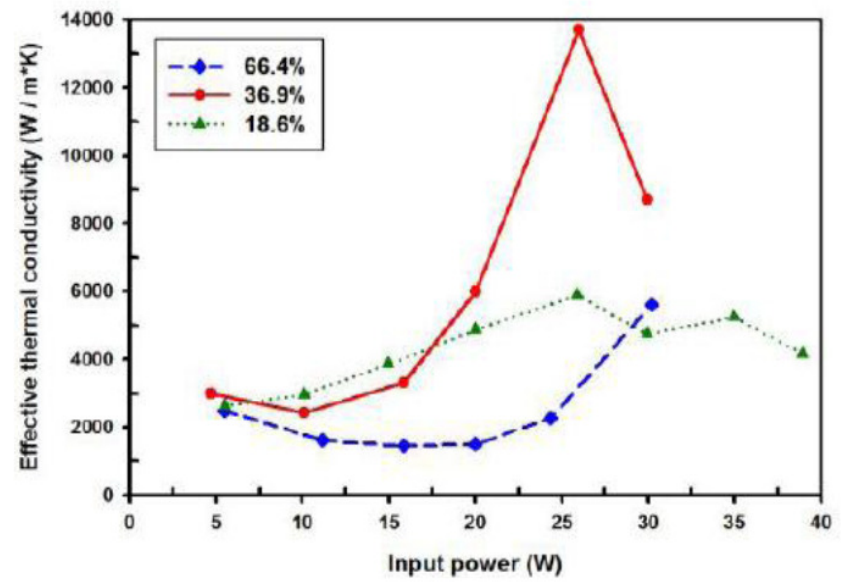

Fig. 10 Effective thermal conductivity as a function of the input power at different filling ratios

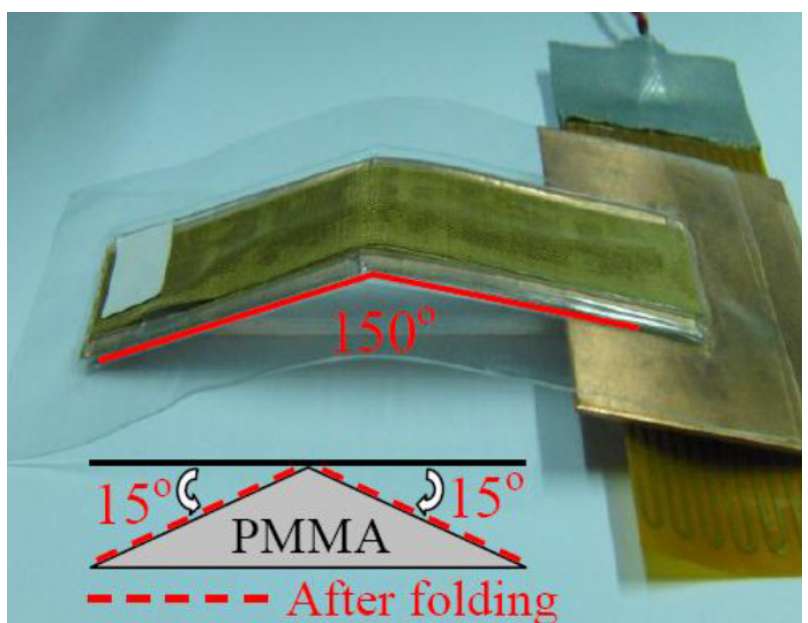

Fig. 11 Thermal resistance test at $30^{\circ}$ bending angle 


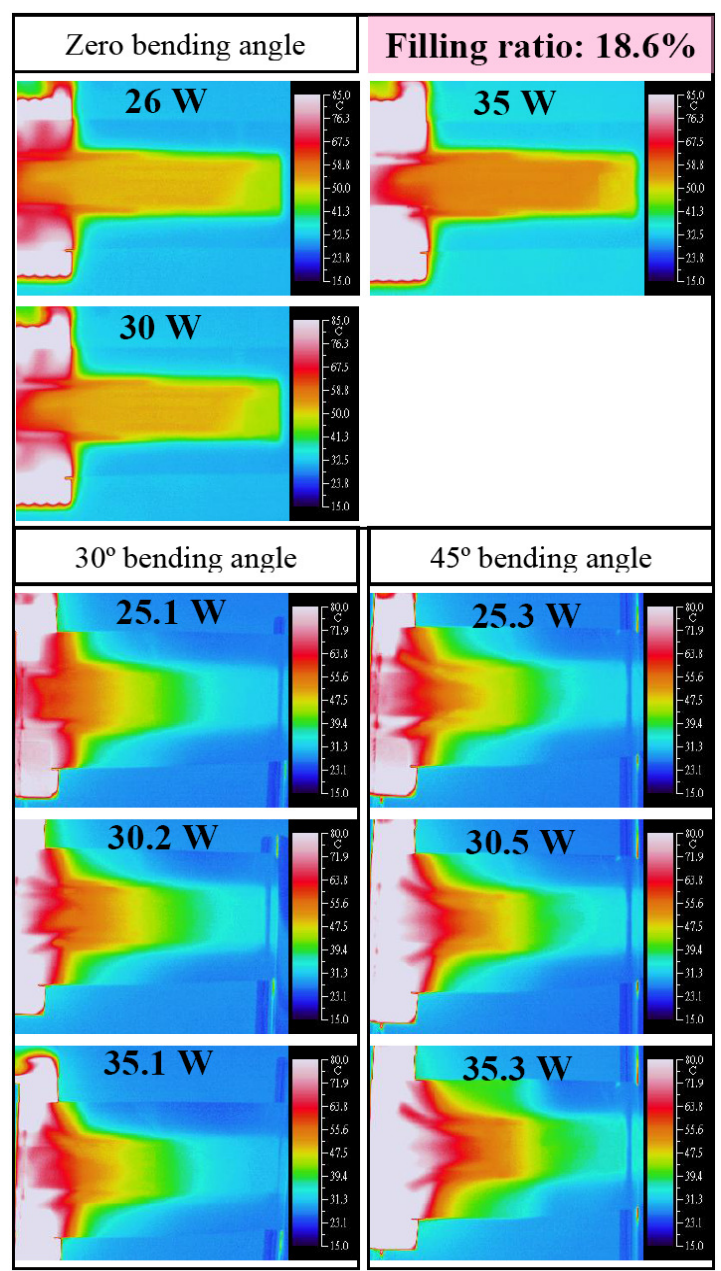

Fig. 12 IR images with different input powers and bending angles

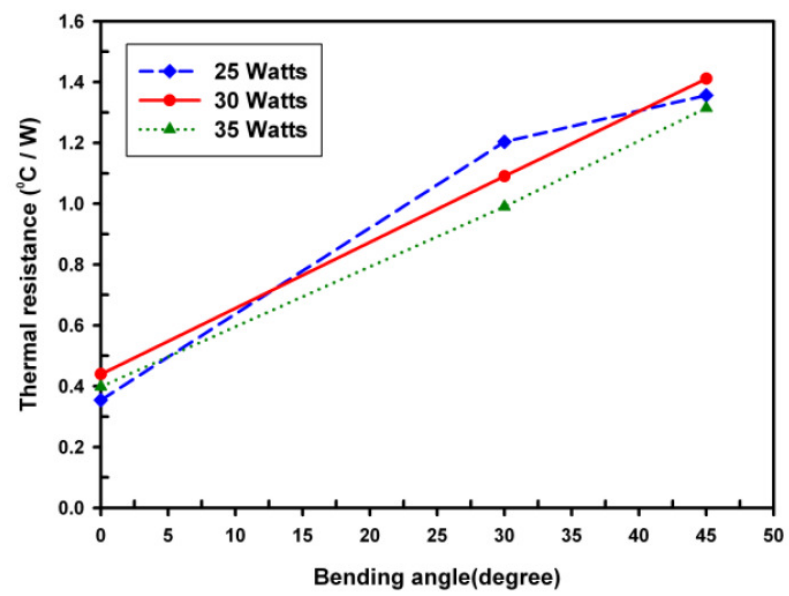

Fig. 13 Thermal resistance with various bending angles at different input powers

\subsection{Effect of Different Bending Angles on Thermal Resistance}

The thermal resistance of the bent heat pipe is measured and compared with the straight one. The photograph of the thermal resistance test at the $30^{\circ}$ bending angle is shown in Fig. 11. A poly(methyl methacrylate) (PMMA) mold with triangular form is used as the supporting structure. The folding line of the MFHP is along the tip of the triangular, and the bending angle is symmetric on both sides.

The IR images of the evaporator for measuring the thermal resistance at different bending angles of $0^{\circ}$ (horizontal), $30^{\circ}$ and $45^{\circ}$ are shown in Fig. 12. The heat is accumulated in the evaporator region when the bending angle increases from $0^{\circ}$ to $30^{\circ}$. When the heat pipe is bent, the cross-sectional area will reduce at the bending section. The methanol vapor will be blocked on the evaporator region and can not be easily delivered to the condenser. Although the thermal resistance can be slightly reduced by increasing the input power, it is still high in general. Accordingly, the thermal resistance will increase with higher bending angles, as shown in Fig. 13. For even larger bending angles $\left(>45^{\circ}\right)$ and input powers $(>45 \mathrm{~W})$, the high vapor pressure will cause the PET to delaminate.

\section{CONCLUSIONS}

A FMHP using PET films has been fabricated in this work. For packaging the heat pipe, a laminator is used to bond the PET films. It is a rapid and low cost fabrication process for manufacturing heat pipe. The steady-state thermal resistance of straight and bent FMHP has been analyzed and discussed. The optimal filling ratio and input power are $36.9 \%$ and $25 \mathrm{~W}$, respectively for the highest thermal conductivity. The fabricated FMHP shows low thermal resistance $\left(0.157^{\circ} \mathrm{C} / \mathrm{W}\right)$ and high effective thermal conductivity $(13261 \mathrm{~W} / \mathrm{m} * \mathrm{~K})$.

\section{ACKNOWLEDGEMENTS}

This work has been sponsored by the National Science Council, Taiwan with the contract number: 98-2221-E-002-126-MY3.

\section{REFERENCES}

Berre, M.L., Launay, S., Sartre, V., and Lallemand, M., 2003, "Fabrication and Experimental Investigation of Silicon Micro Heat Pipes for Cooling Electronics," Journal of Micromechanics and Microengineering, 13(436), 436-441. http://dx.doi.org/10.1088/0960-1317/13/3/313

Dorf, R.C., 2004, The Engineering Handbook, $2^{\text {nd }}$ ed., CRC Press.

El-Nasr, A.A. and El-Haggar, S.M., 1996, "Effective Thermal Conductivity of Heat Pipes," Heat and Mass Transfer, 32(1-2), 97-101. http://dx.doi.org/10.1007/s002310050097

Lim, H.T., Kim, S.H., Im, H.D., Oh, K.H., and Jeong, S.H., 2008, "Fabrication and Evaluation of a Copper Flat Micro Heat Pipe Working under Adverse-Gravity Orientation," Journal of Micromechanics and Microengineering, 18(10), 105013. http://dx.doi.org/10.1088/0960-1317/18/10/105013

Lin, Y.H., Kang, S.W., and Wu, T.Y., 2009, "Fabrication of Polydimethylsiloxane (PDMS) Pulsating Heat Pipe," Applied Thermal Engineering, 29(2-3), 573-580.

http://dx.doi.org/10.1016/j.applthermaleng.2008.03.028

Lips, S., Lefèvre, F., and Bonjour, J., 2010, "Combined Effects of the Filling Ratio and the Vapour Space Thickness on the Performance of a Flat Plate Heat Pipe," International Journal of Heat and Mass Transfer, 53(4), pp. 694-702. http://dx.doi.org/10.1016/j.ijheatmasstransfer.2009.10.022

Oshman, C.J., Shi, B., Li, C., Yang, R.G., Lee, Y.C., and Brigh, V.M., 2009, "Fabrication and Testing of a Flat Polymer Micro Heat Pipe," Proceedings of Transducers '09, Denver, CO, USA.

Sobhan, C.B., Rag, R.L., and Peterson, G.P., 2007, "A Review and Comparative Study of the Investigations on Micro Heat Pipes," International Journal of Energy Research, 31(6-7), pp. 664-688. http://dx.doi.org/10.1002/er.1285

Take, K. and Webb, R.L., 2001, "Thermal Performance of Integrated Plate Heat Pipe with a Heat Spreader," Journal of Electronic Packaging, 123(3), 189-195.

http://dx.doi.org/10.1115/1.1348010 
Tanaka, K. Abe, Y., Nakagawa, M., Piccolo, C., and Savinoe, R., 2009, "Low-Gravity Experiments of Lightweight Flexible Heat Pipe Panels with Self-Rewetting Fluids," Interdisciplinary Transport Phenomena: Fluid, Thermal, Biological, Materials and Space Science, 1161, 554561.

http://dx.doi.org/10.1111/j.1749-6632.2008.04333.x
Yau, Y.H. and Ahmadzadehtalatapeh, M., 2010, "A Review on the Application of Horizontal Heat Pipe Heat Exchangers in Air Conditioning Systems in the Tropics," Applied Thermal Engineering, 30(2-3), 77-84.

http://dx.doi.org/10.1016/j.applthermaleng.2009.07.011 